\title{
USE OF BISPHOSPHONATES AND RISK OF CARDIOVASCULAR EVENTS: A POPULATION-BASED RETROSPECTIVE COHORT STUDY
}

\author{
F. Galimberti ${ }^{1}$, M. Casula ${ }^{1}$, E. Olmastroni ${ }^{1}$, E. Tragni ${ }^{1}$, G. Corrao ${ }^{2}$, L. Scotti ${ }^{2}$, A.L. Catapano ${ }^{1,3}$
}

1 Epidemiology and Preventive Pharmacology Service (SEFAP), Department of Pharmacological and Biomolecular Sciences, University of Milan, Milan, Italy
2 Department of Statistics and Quantitative Methods, Division of Biostatistics, Epidemiology and Public Health, University of Milano-Bicocca, Milan, Italy

\section{BACKGROUND and AIM}

Bisphosphonates are widely used in clinical practice to prevent and treat osteoporosis, as they are able to reduce the excessive osteoclast-mediated bone resorption. Emerging evidence indicates that vascular calcification is an actively regulated process that shares several biological mechanisms with bone mineralization. Therefore it is conceivable that bisphosphonates could interfere in the arterial calcification process and might be able to inhibit atherosclerosis and vascular calcification, which means to be able to reduce the risk of cardiovascular disease.

Aim of the present study was thus to investigate the occurrence of cardiocerebrovascular (CV) events in patients treated with bisphosphonates in a populationbased real-world retrospective cohort study.

\section{METHODS}

Data were retrieved from the administrative healthcare utilization databases of the Italian Lombardy region, and appropriately encrypted: (1) demographic data, (2) outpatient drug prescription data, (3) database on diagnosis at discharge from hospitals.

All beneficiaries of the National Health System, resident in Lombardy of both sex with age $>40$ years who have received a first prescription (index date) for any bisphosphonates (ATC M05BA) between 2003 and 2006, were selected and followed until the first CV event, death or migration, or the end of observational period (2012/12/31).

Exposure to bisphosphonates was evaluated as "proportion of days covered" (PDC).

cumulative number of days

$\mathbf{P D C}=$ with medication available (DDD)

number of days of follow-up (>80\%) based on PDC values.

The association between time-varying cumulative exposure to bisphosphonates and hospitalization for any CV events was assessed using multivariate Cox proportional hazard model (adjusted hazard ratios [aHR] and 95\% confidence intervals).

The model was adjusted for age, sex, comorbidities (atrial fibrillation, fractures, and Charlson Comorbidity Index), and concomitant CV treatments (antidiabetic, antihypertensive, lipid-lowering, and antithrombotic medications).

\section{RESULTS}

A total of 82,704 subjects (mean age 70.7 years; female $87.0 \%$ ) were enrolled in the study. Within this cohort, we identified 13,337 (16.1\%) individuals with a hospitalization for ischemic heart disease $(\mathrm{N} 6508)$ and/or non-haemorrhagic cerebrovascular disease ( $\mathrm{N} 7298)$, occurred on

\begin{tabular}{|c|c|c|}
\hline \multicolumn{2}{|l|}{$\begin{array}{l}\text { Table } 1 \\
\text { Female sex. } \mathrm{N} \text { (\%) }\end{array}$} & TOTAL $(\mathrm{N}=\mathbf{8 2}, \mathbf{7 0 4})$ \\
\hline \multicolumn{2}{|l|}{ Female sex, $\mathrm{N}(\%)$} & $71,936(87.0)$ \\
\hline \multicolumn{2}{|l|}{ Age, mean (SD) } & $70.7(10.6)$ \\
\hline \multirow{3}{*}{ Age, $N(\%)$} & $41-60$ years & $14,483(17.5)$ \\
\hline & $61-80$ years & $53,258(64.4)$ \\
\hline & $>80$ years & $14,963(18.1)$ \\
\hline \multirow{6}{*}{ Bisphosphonates at index date, $\mathrm{N}(\%)$} & Etidronic acid & $217(0.26)$ \\
\hline & Clodronic acid & $1114(1.35)$ \\
\hline & Alendronic acid & $55,480(67.08)$ \\
\hline & Ibandronic acid & $1162(1.41)$ \\
\hline & Risedronic acid & $18,250(22.07)$ \\
\hline & Neridronic acid & $6481(7.84)$ \\
\hline \multirow{3}{*}{ Charlson score, $\mathrm{N}$ (\%) } & 0 & $72,113(87.2)$ \\
\hline & 1 & $6846(8.3)$ \\
\hline & $\geq 2$ & $3749(4.5)$ \\
\hline \multicolumn{2}{|l|}{ Previous use of glucocorticoids, N (\%) } & $19,835(24.0)$ \\
\hline \multicolumn{2}{|c|}{ Previous use of other anti-osteoporotic drugs, N (\%) } & $216(0.3)$ \\
\hline \multicolumn{2}{|l|}{ Use of lipid-lowering drugs, N (\%) } & $29,181(35.3)$ \\
\hline Use of antidiabetic drugs, $\mathrm{N}(\%)$ & & $11,331(13.7)$ \\
\hline \multicolumn{2}{|l|}{ Use of antihypertensive drugs, $\mathrm{N}(\%)$} & $67,457(81.6)$ \\
\hline \multicolumn{2}{|l|}{ Use of antithrombotic drugs, $\mathrm{N}(\%)$} & $55,259(66.8)$ \\
\hline \multicolumn{2}{|l|}{ Hospitalization for fractures, N (\%) } & $6676(8.1)$ \\
\hline \multicolumn{2}{|c|}{ Hospitalization for atrial fibrillation, $\mathrm{N}(\%)$} & $9318(11.3)$ \\
\hline \multirow{2}{*}{ CV Events, N (\%) } & Cardiovascular event & $6508(7.9)$ \\
\hline & Cerebrovascular event & $7298(8.8)$ \\
\hline
\end{tabular}
average (SD) 3.5 (2.3) years after the index date (Table 1). In the multivariate adjusted analysis, subjects exposed for a period ranged between $41-80 \%$, or $>80 \%$, showed significantly reduced risk of $\mathrm{CV}$ events, compared with individuals with an exposure $\leq 40 \%$ (Table 2 ).

\begin{tabular}{|c|c|c|c|}
\hline Table 2 & & aHR & $95 \% \mathrm{Cl}$ \\
\hline & $\mathrm{PDC} \leq 40 \%$ & 1 & Ref \\
\hline Exposure & $40 \%<P D C \leq 80 \%$ & 0.950 & $0.905-0.998$ \\
\hline & PDC $>80 \%$ & 0.754 & $0.706-0.805$ \\
\hline SoY & Female & 1 & Ref \\
\hline sex & Male & 0.645 & $0.607-0.684$ \\
\hline Age & & 1.080 & $1.077-1.083$ \\
\hline Fractures & & 1.232 & $1.146-1.323$ \\
\hline Atrial fibrillation & & 1.639 & $1.539-1.745$ \\
\hline Drugs for diabetes & & 1.001 & $1.001-1.002$ \\
\hline Drugs for hypertension & & 1.001 & $1.000-1.001$ \\
\hline Drugs for hypercholesterolemia & & 1.002 & $1.001-1.002$ \\
\hline Antithrombotic drugs & & 1.005 & $1.004-1.005$ \\
\hline & Glucocorticoids drugs & 1.099 & $1.045-1.156$ \\
\hline Use of other drugs (vs. no use) & Other bone drugs & 0.906 & $0.577-1.421$ \\
\hline & 0 & 1 & Ref \\
\hline Charlson comorbidity index & 1 & 1.423 & $1.330-1.522$ \\
\hline & $\geq 2$ & 1.833 & $1.689-1.989$ \\
\hline
\end{tabular}

In the analyses performed separately considering cardiovascular and cerebrovascular events as outcomes, a remarkable reduction of the

$$
\text { Fol }
$$
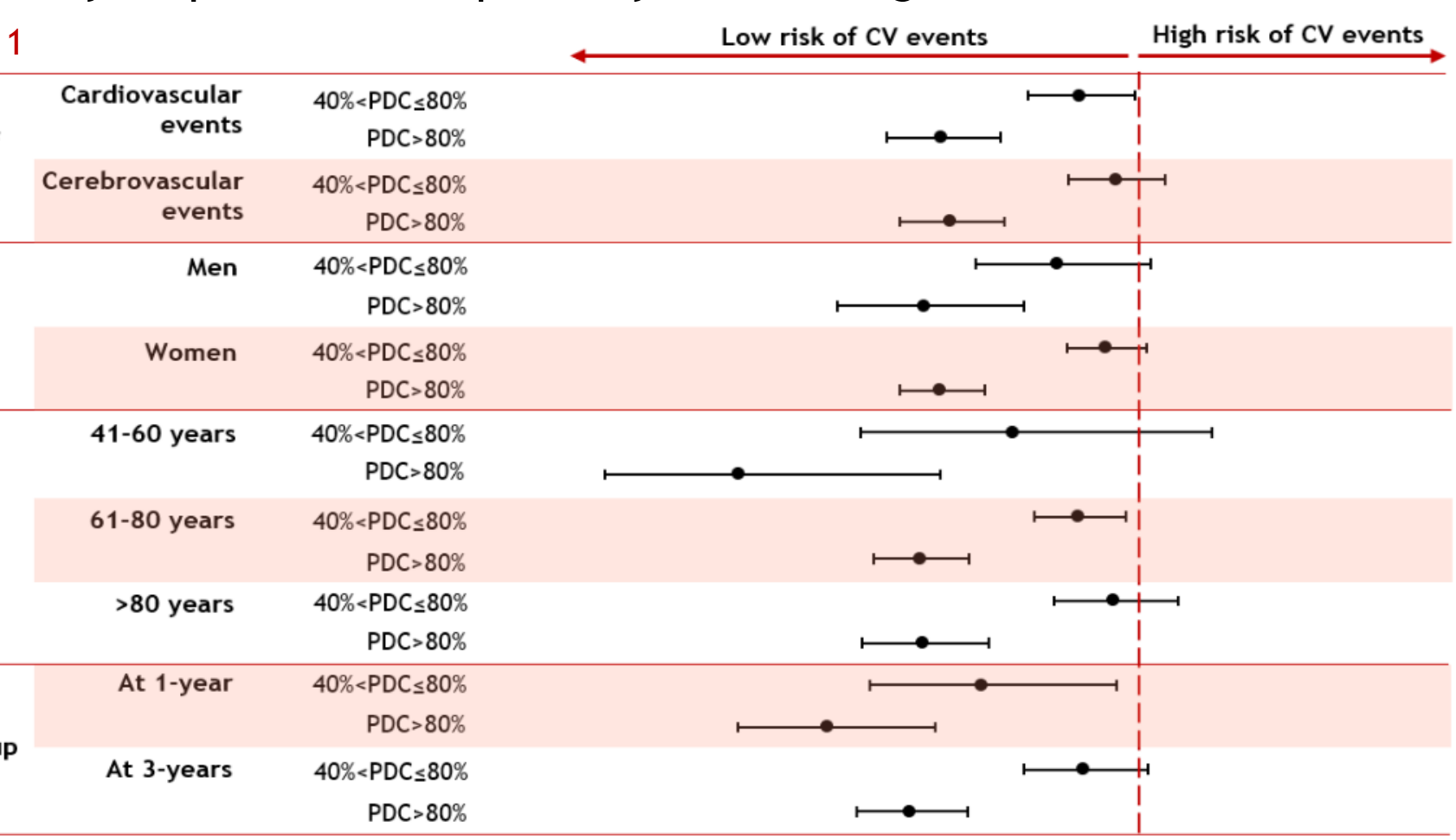

incidence for both outcomes was observed in subjects with an exposure higher than $80 \%$. The decrease of the $\mathrm{CV}$ risk was also confirmed in all the strata by potential influencing factors, such as sex, age, or follow-up duration (Figure 1).

Finally, as sensitivity analysis, the primary analysis was also performed using different windows of adherence (PDC $<25 \%$, from $25 \%$ to $49 \%$, from $50 \%$ to $74 \%$, and $\geq 75 \%$ ) in order to avoid the arbitrary nature of PDC categorization. Results (Table 3) were consistent with the main findings.

\begin{tabular}{|llcc|}
\hline Table 3 & & aHR & $95 \% \mathrm{Cl}$ \\
\cline { 2 - 4 } Exposure & $\mathrm{PDC}<25 \%$ & 1 & Ref \\
\cline { 2 - 4 } & $25 \% \leq \mathrm{PDC}<50 \%$ & 0.941 & $0.885-1.001$ \\
\cline { 2 - 4 } & $50 \% \leq \mathrm{PDC}<75 \%$ & 0.927 & $0.873-0.984$ \\
\cline { 2 - 4 } & $\mathrm{PDC} \geq \mathbf{7 5 \%}$ & $\mathbf{0 . 7 5 6}$ & $\mathbf{0 . 7 0 9 - 0 . 8 0 5}$ \\
\hline
\end{tabular}

\section{CONCLUSIONS}

These results suggest a strong reduction of cardiovascular events with increasing number of days covered by bisphosphonate treatment. We believe that it is important to consider bisphosphonates, and a strict adherence to this treatment, as having a potential effect also in the prevention of CV events.

Additional studies are needed to confirm the protective CV effect of bisphosphonate therapy and to specifically address the mechanism by which bisphosphonates use could influence cardiovascular disease.

\section{Corresponding author:}

Federica Galimberti, PharmD

SEFAP - Epidemiology and Preventive Pharmacology Service - Department of Pharmacological and Biomolecular Sciences, University of Milan federica.galimberti@unimi.it 